\title{
Developing Web-Based Application of Sales Forecasting System Using Triple Exponential Smoothing Method For Small and Medium Garment Enterprises
}

\author{
I Ketut Suwintana ${ }^{1}$, I G A Oka Sudiadnyani² \\ Accounting Department \\ Politeknik Negeri Bali \\ Bali, Indonesia \\ ${ }^{1}$ tutswint@pnb.ac.id, ${ }^{2}$ okasudiadnyani@pnb.ac.id
}

\author{
N G A P H Saptarini ${ }^{3}$ \\ Information System Department \\ Politeknik Negeri Bali \\ Bali, Indonesia \\ 3ayu.harry@pnb.ac.id
}

\begin{abstract}
Accurate sales forecasting is needed by all companies, including by small and medium garment enterprises to be used in financial management. Accurate sales forecasting will make better inventory management, which indirectly gives benefit to the company. Limitation of human in forecasting sales without using tools in form of computer application becomes an obstacle to predict sales accurately. This study aimed at developing web-based application of sales forecasting system using triple exponential smoothing method for small and medium garment enterprises. This application was developed by using PHP programming language and the data was stored in MySQL database. Method of application development used System Development Life Cycle (SDLC) with steps: requirements analysis, design, development, and testing. Score of forecasting error level was calculated by using MAPE (Mean Absolute Percentage Error), and RMSE (Root Mean Square Error). The result of this study was web-based application of sales forecasting system using triple exponential smoothing method which was tested by using sales data of small and medium garment enterprises in January 2016 until December 2017.
\end{abstract}

Keywords-triple exponential smoothing; forecasting; webbased application

\section{INTRODUCTION}

Determining production number is a part of strategy in financial management for Small and Medium Garment Enterprises. In determining number of productions, the company should be able to forecast the upcoming sales. If the company made mistake in forecasting the sales, there could be undesirable things happen. For example, the company could not fulfill the customer's demand which suddenly rises. Otherwise, company makes over production in which customer's demand is not equal to the company's estimation so the product cannot be sold. It can harm the company. So, sales forecast is the basis of financial planning [1].

Therefore, it is needed a computer program as the implementation of forecast method to help Small and Medium Garment Enterprises in getting the value of sales forecast accurately and fast. One of the common methods of forecasting is the Exponential Smoothing methods. The method is very important in the statistical methods and procedures addressing noise and random errors [2]. Exponential Smoothing methods can be defined generally as fine-tuning or smoothing data where there is interference. It is a kind of estimation process which is proven through the study of cases that depend on time or change with time [3].

Method of Triple Exponential Smoothing (Brown's one parameter quadratic) is the development of two Linier Multiply exponential technique of Parameter Holt upon season by inserting third smoothing to adjust seasonal component. This method is based on quadratic function is used to forecast data by a basic trend pattern. If the data pattern basis is higher quadratic, cubic or ordo so it is used additional smoothing level (triple smoothing) and enforcing quadratic forecasting equation.

The exponential smoothing method describes a class of forecasting methods. Each has the property that forecasts are weighted combinations of past observations, where recent observations are given relatively more weight than older ones [4]. The triple exponential smoothing method provides good forecasts with simple formulations, allowing the incorporation of error, trend components in a comprehensive manner [5-8].

This study aimed at developing web-based application of sales forecasting system using triple exponential smoothing method (Brown's one parameter quadratic).

\section{METHODOLOGY}

\section{A. Step of Aplication Development}

The developed application is a web-based application. The method of application development used System Development Life Cycle (SDLC) with steps: requirements analysis, design, development, and testing. Application development used PHP programming language and data storage in MySQL database. Testing of application used data of sales in 2015 until 2017. 


\section{B. Method of Sales Forecasting}

The method used to forecast the sales in this application development was triple exponential smoothing method (Brown's one parameter quadratic), with the following steps.

1. Calculating value of first exponential smoothing

$$
S_{t}^{\prime}=\alpha Y_{t}+(1-\alpha) S_{t-1}^{\prime}
$$

2. Calculating value of second exponential smoothing

$$
S_{t}^{\prime \prime}=\alpha S_{t}^{\prime}+(1-\alpha) S_{t-1}^{\prime \prime}
$$

3. Calculating value of third exponential smoothing

$$
S_{t}^{\prime \prime \prime}=\alpha S_{t}^{\prime \prime}+(1-\alpha) S_{t-1}^{\prime \prime \prime}
$$

4. Calculating total smoothing

$$
a_{t}=3 S_{t}^{\prime}-3 S_{t}^{\prime \prime}+S_{t}^{\prime \prime \prime}
$$

5. Calculating trend smoothing

$$
b_{t}=\left[\alpha /\left\{2(1-\alpha)^{2}\right\}\right]\left[(6-5 \alpha) S_{t}^{\prime}-(10-8 \alpha) S_{t}^{\prime \prime}+(4-3 \alpha) S_{t}^{\prime \prime \prime}\right]
$$

6. Calculating quadratic smoothing

$$
c_{t}=\left[\alpha^{2} /(1-\alpha)^{2}\right]\left[S_{t}^{\prime}-2 S_{t}^{\prime \prime}+S_{t}^{\prime \prime \prime}\right]
$$

7. Determining value of forecasting

$$
F_{t+m}^{,}=a_{t}+b_{t}(m)+0,5 c_{t} m^{2}
$$

In which:

$S_{t}{ }^{\prime} \quad=$ First smoothing period $\mathrm{t}$

$\alpha=$ Smoothing Constanta $(0<\alpha<1)$

$Y_{t} \quad=$ Real value of period $\mathrm{t}$ or actual data

$S_{t}^{\prime \prime} \quad=$ Second smoothing period $\mathrm{t}$

$S_{t}^{\prime \prime \prime}=$ Third smoothing period $\mathrm{t}$

$a_{t} \quad=$ Total smoothing

$b_{t} \quad=$ Trend smoothing

$c_{t} \quad=$ Quadratic smoothing

$F^{\prime}{ }_{\mathrm{t}+\mathrm{m}}=$ Forecasting value

$m \quad=$ Future period

\section{Forecasting Errors}

There are some methods to measure compatibility and accuracy of forecasting [9]. This study used MAPE (Mean Absolute Percentage Error), and to calculate value of forecasting error level. MAPE is absolute value from errors measurement as percentage of forecasting error [10]. Calculation formula can be seen in (1), (2), and (3). This gap is calculated in percentage upon real data.

$$
\begin{gathered}
P E=\left(\frac{Y_{t}-F_{t}}{Y_{t}}\right)(100) \\
M P E=\sum_{i=1}^{n} \frac{P E_{t}}{n}
\end{gathered}
$$

$$
M A P E=\sum_{n-1}^{n} \frac{\left|P E_{t}\right|}{n}
$$

In which:

$$
\begin{array}{ll}
t & =\text { index which states time period } \\
y & =\text { actual value } \\
F & =\text { forecast on period } \mathrm{m} \text { in the future } \\
P E & =\text { Percentage Error } \\
M P E & =\text { Mean Percentage Error } \\
n & =\text { total of data }
\end{array}
$$

Mean Squared Error (MSE) is mean square score of forecast error. Formula to calculate MSE can be seen in (11). Value of Root Mean Square Error (RMSE) showed difference between forecast result and the forecasted result. Getting smaller the value of RMSE so the value of forecasting is getting accurate. Formula to calculate value of RMSE can be seen in (12).

$$
M S E=\frac{1}{N} \sum_{t=h}^{N}\left(Y_{t}-\hat{Y}_{t}\right)^{2}
$$

$$
R M S E=\sqrt{\frac{\sum\left(Y_{t}-\hat{Y}_{t}\right)^{2}}{N}}
$$

In which:

$\begin{array}{ll}N & =\text { number of samples } \\ Y_{t} & =\text { actual value } \\ \hat{Y}_{t} & =\text { predicted value } \\ M S E & =\text { Mean Square Error }\end{array}$

\section{IMPLEMENTATION}

This sales forecasting application was developed by using PHP programming language (framework CodeIgniter) with MySQL database. Application flow was started from the use of inputting sales data from small and medium garment enterprises as early information of calculation. The more sales data inputted into application, the more accurate result of the forecasting is gained from the application. It is suggested that the inputted real sales data minimum 6 periods. Next the application will search $\alpha$ optimum value by testing $\alpha$ value from 0.001 until 0.999 . There is smoothing calculation for each $\alpha$ value with (1), (2), (3) and searches value of MSE. Optimum value is $\alpha$ which produces the lowest MSE value. Further step is the application conducts forecasting process by using (4), 
(5), (6), (7). The result of forecasting is stored in MySql database. This application can also present forecasting error testing for the past sales data with MAPE and RMSE methods. Application Flowchart can be seen in Fig. 1.

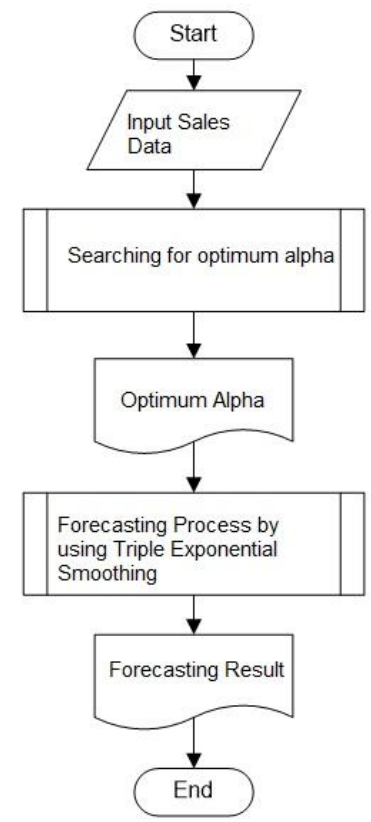

Fig. 1. Application Flowchart

Testing of this sales forecast application uses sales data from Small and Medium Garment Enterprises "CV. Sahabat Sejati Embroidery" in January 2016 until December 2017, shown in Table I.

TABLE I. SALES DATA IN JANUARI 2016 UNTIL DECEMBER 2017

\begin{tabular}{|l|r|r|r|r|r|}
\hline \multirow{2}{*}{ Month } & \multicolumn{5}{|c|}{ The Amount Sold } \\
\cline { 2 - 6 } & T-shirt A & T-shirt B & T-shirt C & T-shirt D & T-shirt E \\
\hline Jan 2016 & 752 & 511 & 679 & 121 & 456 \\
\hline Feb 2016 & 950 & 478 & 365 & 102 & 308 \\
\hline Mar 2016 & 1,068 & 939 & 1,144 & 229 & 802 \\
\hline Apr 2016 & 975 & 635 & 545 & 348 & 363 \\
\hline May 2016 & 841 & 511 & 766 & 231 & 799 \\
\hline Jun 2016 & 800 & 876 & 389 & 105 & 403 \\
\hline Ju1 2016 & 562 & 654 & 678 & 109 & 877 \\
\hline Aug 2016 & 343 & 762 & 783 & 201 & 899 \\
\hline Sep 2016 & 605 & 754 & 678 & 209 & 877 \\
\hline Oct 2016 & 772 & 899 & 890 & 109 & 987 \\
\hline Nop 2016 & 1,014 & 876 & 980 & 205 & 751 \\
\hline Dec 2016 & 823 & 743 & 661 & 210 & 901 \\
\hline Jan 2017 & 778 & 654 & 782 & 190 & 877 \\
\hline Feb 2017 & 686 & 807 & 867 & 187 & 766 \\
\hline Mar 2017 & 736 & 578 & 455 & 195 & 542 \\
\hline Apr 2017 & 646 & 799 & 786 & 206 & 543 \\
\hline May 2017 & 688 & 678 & 890 & 302 & 654 \\
\hline Jun 2017 & 512 & 899 & 765 & 210 & 876 \\
\hline Jul 2017 & 1,223 & 878 & 987 & 327 & 654 \\
\hline Aug 2017 & 790 & 765 & 889 & 267 & 653 \\
\hline Sep 2017 & 692 & 645 & 675 & 190 & 563 \\
\hline Oct 2017 & 777 & 762 & 761 & 198 & 456 \\
\hline Nop 2017 & 808 & 810 & 880 & 216 & 356 \\
\hline Dec 2017 & 653 & 859 & 975 & 321 & 776 \\
\hline
\end{tabular}

Fig. 2 shows the output of the application for sales forecast using triple exponential smoothing method.

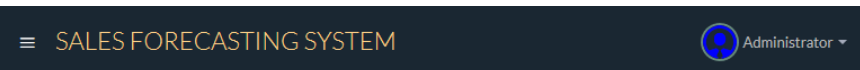

* FORECASTING

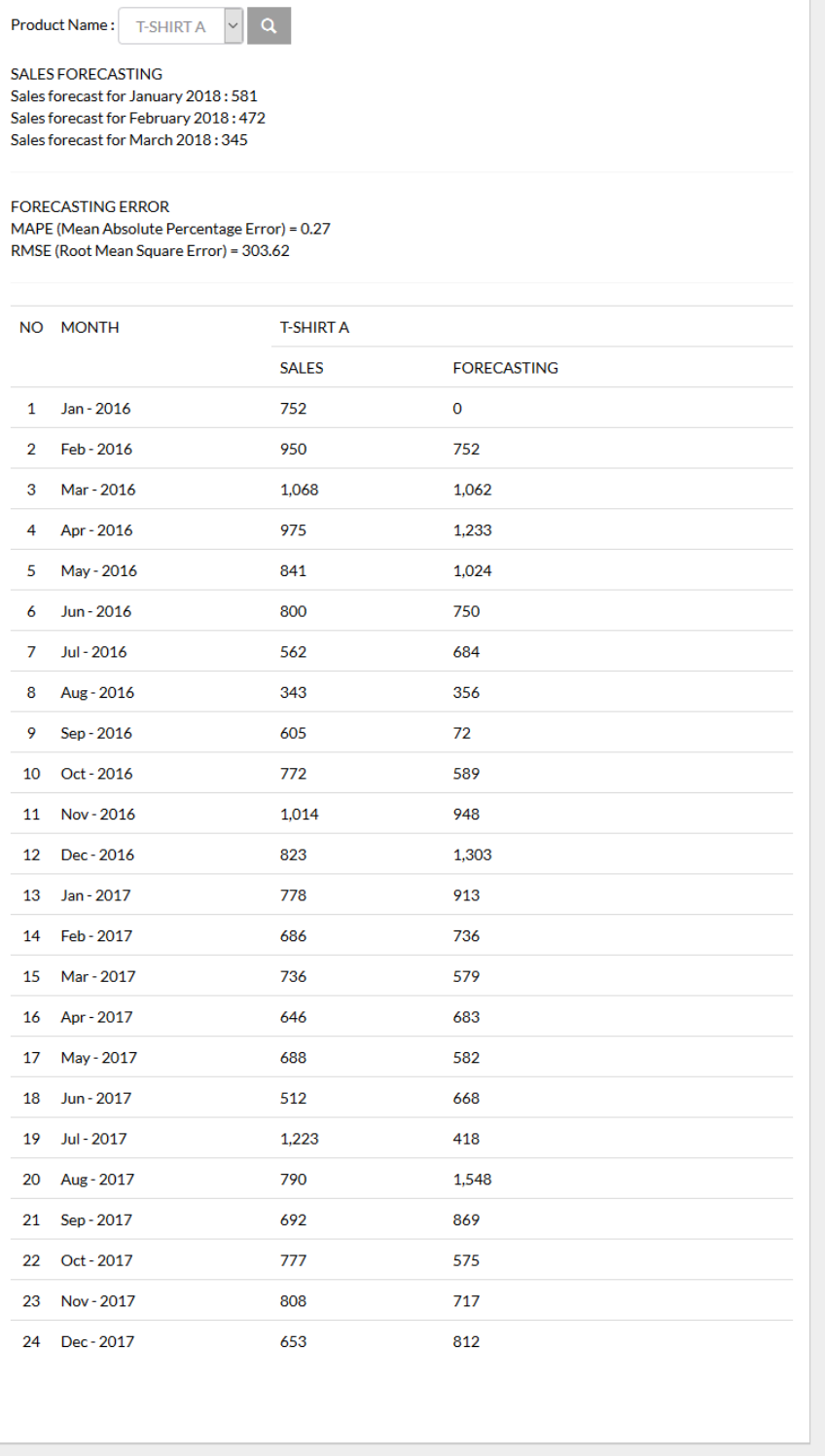

Fig. 2. The output of the application

\section{CONCLUSION}

This web-based application of sales forecasting system using triple exponential smoothing method (Brown's one parameter quadratic) was developed by using PHP programming language and the data is stored in MySQL database. This application could determine the use optimum $\alpha$ perimeter value. This application was tested by using sales data of small and medium garment enterprises from January 2016 until December 2017. The sales forecasting error was tested by 
using MAPE (Mean Absolute Percentage Error), and RMSE (Root Mean Square Error) methods.

For further study, this application can be developed by adding other forecasting method. It enables to conduct comparison analysis between some forecasting methods to get maximum result.

\section{ACKNOWLEDGMENT}

The authors would like to thank you to Politeknik Negeri Bali and the Ministry of Research and Technology of Higher Education of the Republic of Indonesia for the funding of this research.

\section{REFERENCES}

[1] R. Burns and J. Walker, "The Sales Forecast and Financial Management in the Small Manufacturing Firm", J. Enterp. Financ., vol. 6, pp. 115$128,2001$.

[2] A.A. Hamooodat, "Comparison between exponential Smoothing model and Intervention method on international prices of barley", Tikrit J. pur. sci., vol. 18, pp.255-262, 2013.

[3] A. Alrahamneh, "Using Single and Double Exponential Smoothing for Estimating The Number of Injuries and Fatalities Resulted From Traffic
Accidents in Jordan (1981-2016)", Middle-East J. of Sci. Res., vol. 25, pp.1544-1552, 2017.

[4] L. Wu, S. Liu, and Y. Yang, "Grey double exponential smoothing model and its application on pig price forecasting in China", Appl. Soft Comput., vol.39, pp. 117-123, February 2016.

[5] J.W. Taylor, "Density forecasting of intraday call center arrivals using models based on exponential smoothing", Manag. Sci., vol.58, pp. 534549, March 2012.

[6] W. Romeijnders, R. Teunter, and W.V Jaarsveld, "A two-step method for forecast-ing spare parts demand using information on component repairs", Eur. J. Oper. Res., vol.220, pp. 386-393, July 2012.

[7] G. Li, Z. Cai, X. Kang, Z. Wu, and Y. Wang, "ESPSA: a predictionbased algorithm for streaming time series segmentation", Expert Syst. Appl., vol.41, pp. 6098-6105, October 2014.

[8] A.O. Akuno, M.O. Otieno, C.W. Mwangi and L.A. Bichanga, "Statistical Models for Forecasting Tourists' Arrival in Kenya", Open J. Stat., vol 5, pp. 60-65, 2015.

[9] N.A. Elmunim, M. Abdullah, A.M. Hasbi, and S.A. Bahari, "Short-term forecasting ionospheric delay over UKM, Malaysia, using the HoltWinter method", IEEE Int. Conf. Space Sci. Commun., pp. 106-109, July 2013.

[10] W. Setiawan, E. Juniati, and I. Farida, "The Use of Triple Exponential Smoothing Method (Winter) in Forecasting Passenger of PT Kereta Api Indonesia with Optimization Alpha, Beta, and Gamma Parameters", 2nd Int. Conf. Sci. Inf. Tech., pp.198-202, October 2016. 